\title{
A Proposed Model for Understanding and Supporting Creativity and Mathematical Talent Development
}

\author{
Majed Wadaani \\ College of Education, Jazan University, Saudi Arabia
}

Copyright $\mathrm{C} 2019$ by authors, all rights reserved. Authors agree that this article remains permanently open access under the terms of the Creative Commons Attribution License 4.0 International License

\begin{abstract}
Research on education has been focused on creativity and talent development in order to better understand underlying concepts and suggest teaching practices that lead students to a higher level for best utilization of their potentials. Giftedness in mathematics is a major focus for many researchers because of the importance of mathematics in scientific development and innovation. Creativity, on the other hand, is considered not only as a major component of giftedness, but also as the essence of mathematics that should be fostered for all students. This research study further analyzed creativity and giftedness in mathematics, and synthesized rational support of a proposed model to better understand and support creativity and mathematical talent development in general education schools; it also discussed preliminary requirements for effective use of the proposed model based on teachers' perspectives. The major purpose is to contribute to enhancing school trends toward nurturing creativity for all students and meeting the needs of gifted mathematics students, utilizing broad conceptions of creativity and giftedness, and internalizing positive beliefs about student capability for success in mathematics.
\end{abstract}

Keywords Creativity, Mathematics Education, Gifted Education, Talent Development

\section{Introduction}

Nations around the world seek to maintain a global leadership position in productivity and scientific development by focusing on youth development. As such, youth, as future leaders for any nation, need to be exposed to educational experiences at early ages, which helps them become more independent, analytical, critical, creative, cooperative, and thus personally and socially successful in dealing with real-life problems and needs. These significant skills are very important to be nurtured in general classrooms for all students, with additional enrichment opportunities for those who express high academic abilities and potential giftedness (Wadaani, 2015a).

Allowing youth to use their intellectual potential at early levels of education is highly critical; as special efforts at university levels often are not effective with students who have experienced continued earlier boredom and frustration (Stanley, 1991). Literature also includes that creativity, as an attitude toward life and development, is more obvious and easier to be nurtured in young children than it is in older children and adults who have been affected by environments that encourage intellectual conformity, suppress creativity, and overlook talent potential (e.g., Torrance, 1995; Beghetto \& Kaufman, 2007; Sternberg, Kaufman, \& Grigorenko, 2008). Therefore, creativity is supposed to be an essential part of each early education curriculum.

Creativity is described as an important multifaceted phenomenon that can be developed for all students in different areas toward different levels (Wadaani.2015b; Davis, 2004). For example, Treffinger, Young, Selby, and Shepardson (2002) stated that, "Creativity can be expressed in a nearly infinite number of ways in human behavior and has its origins in several components of individual and social experience" (p. 5). Plucker, Beghetto, and Dow (2004) added that "creativity is an important component of problem-solving, healthy social and emotional well-being, and scholastic and adult success" (p. 83). Therefore, it is important that creativity be nurtured for all students, and further supported with gifted students in order to help students become continued creative learners who can make well informed critical decisions and choices in unexpected situations (Torrance, 1995; Brinkman, 2010; Sternberg, 2010; Sriraman, Yaftian, \& Lee, 2011; Wadaani et. al., 2016).

On the other hand, giftedness in mathematics has been a global great interest to look for and invest in. The National Council of Teachers of Mathematics NCTM (1980) stated that "outstanding mathematical ability is a precious societal resource, sorely needed to maintain leadership in a 
technological world" (p. 18). Maintaining world influential status and making consistent progress requires education systems that effectively nurture creativity and further develop mathematical talent (Mann, 2005); responding to the essential roles that mathematics plays in the development of sciences, technology, economics, and various branches of industry (Leikin, 2009). Accordingly, schools and teachers face a major commitment to respond to the need for nurturing students' creativity and further supporting those with potential giftedness in mathematics.

As stated by Milgram and Hong (2009), "societies that do not make every effort to assure that the potential talents of young people are utilized are losing their most valuable natural resource: human capital" (p. 161). Therefore, this research study is a kind of effort that may fill a part of the gap in this issue where the literature is reviewed and supportive information is synthesized for a proposed model designed for understanding and supporting the development of creativity and talent in mathematics hoping to lead to promising effective instructional practices in schools. The proposed model is a developmental model designed in order to open windows through which multiple educational objectives can be achieved. It is based on internalizing education as a process of human development, and mathematics as an important field in scientific development. It also provides foundations for a sequence of teaching focus aspects that are significant not only for those who have potential giftedness but also significant for all students as the atmosphere of creativity enhances achievement for all.

The proposed model has all students in the first part where the focus is teaching for creativity development TCD; teaching for creativity enhances authentic learning and facilitates real achievement for all students (Wadaani,2015a, Wadaani,2015b; Sheffield, 2013; Bahar \& Maker, 2011; Burleson, 2006); creativity here represents overall human development toward self-actualization. Self-actualization as a motive of creativity was defined by Maslow (1943) as "the desire for self-fulfillment and being everything that one is capable of becoming" (p.382). The second part of the model entails teaching for mathematical talent development TMTD, where students with high potentials receive a type education that extends the efforts of developing creativity in the first part. By further developing mathematical abilities, including mathematical creativity, leading them to invest on their giftedness, become talented and future mathematicians who represent human resources that all nations always seek to attain. The two part of the model TCD+TMTD connect and function together as one process, which gives us the whole model, Teaching for Creativity and Mathematical Talent Development T-CMTD.

\section{Research Problem and Questions}

Misunderstanding about nurturing creativity and talent development widely exist among teachers (Wadaani, 2015a), and there is still a need for more theoretical foundations and applied models that can assist teachers in getting clear positive understanding and play their roles in human development at schools. In this study, the researcher tried to synthesize literature in creativity and mathematics gifted education to design a proposed model for understanding and supporting hypothesized development phases of creativity and mathematical talent, through which appropriate teaching practices are presented, and requirements for its effective application are discussed based on teachers' perspectives. The major purpose is to enhance school trends and teachers' attitudes toward making creativity and mathematical talent development a high priority educational goal with clear understanding of underlying concepts. As such, the current research study is guided by the following questions:

1. What are the features of the model that can lead mathematics teachers to better understand and support creativity and mathematical talent development in general education schools?

2. What are the preliminary requirements for effective application of this model in the actual environments of general education schools?

\section{Significance}

Gifted individuals mostly are those who contribute to the large part of improving many life aspects by solving problems creatively, developing genuine innovations, and by leading communities to productivity. Therefore, effective gifted education is an important issue worldwide, and at the center of this issue is creativity as the most important topic in the education of gifted and talented children (Davis et. al., 2011). Moreover, in the current century, mathematics teachers face a major educational commitment to raise students' creativity and nurture giftedness in mathematics in order to play the expected role in enhancing society development and scientific productivity. However, the findings of previous studies included that teachers' perceptions and attitudes toward supporting creativity and talent development were not at the desired level with unclear image of students' creativity and giftedness (Wadaani.2015a).

Accordingly, the importance of this research study appears here as an effort to provide a model that can help teachers understand creativity and giftedness in a way that allows them effectively support talent development for students. This kind of model is significant theoretically because it will move the scientific discussion forward in the field, and it is also practically significant because it provides all teachers with a clear simple image of how promising students can be supported to move through proposed talent development stages. 


\section{Method and Procedures}

In order to build a model that facilitates understanding and supports creativity and mathematical talent development in general education schools, the researcher conducted a deep analysis of relevant literature and previous studies. The major theories about creativity and giftedness are described and connected for common themes. Then, the rationales for a proposed model were extracted and used as bases for building the T-CMTD model. The first version of the model was presented to four specialists in the field of mathematics and gifted education for their feedback; the common recommendations were utilized for improving the outcome and getting the final version of the model. After that, a sample of mathematics teachers was needed to continue the validation process and get answers for the second question. A convenience sample of mathematics teachers was sought to participate in this research; where the researcher sent invitation messages for participation to accessible teachers from Jazan Region, Saud Arabia, for voluntary participation. The researcher was able to have a total of 14 mathematics teachers agreed to participate. Accordingly, the final version of the model was presented to a group of nine teachers for open discussion; the main purpose in this procedure was to ensure that all terms included in the model are clear, and connections of its components are easily understandable for the target population; the research population hers is general education mathematics teachers. Results from the teacher group discussion did not yield any major changes needed in the model.

To get data for the second question of this research study, a focus group interview was conducted with other five mathematics teachers from the sample who are not included in the previous validity procedure. The focus group interview aimed at getting teachers' perspectives about the preliminary requirements for effective utilization of the proposed model in current environments of general education schools. Necessary descriptive introduction was provided; then, the focus group interview started around the following major question: what are the preliminary requirements for effective application of T-CMTD model in the actual environments of general education schools? Other follow-up and open-ended questions were utilized based on the presented feedback to have teachers deeply reflect on the application requirements of the proposed model and share their perspectives in a comfortable situation. Qualitative data from the focus group interview was transcribed and analyzed for finding patterns and themes; then, common elements were identified representing teachers' perspectives about the preliminary requirements for effective utilization of the proposed model.

\section{Review of Literature}

The National Council of Teachers of Mathematics
NCTM (2000) pointed out that "in this changing world, those who understand and master mathematical abilities will have significantly enhanced opportunities and options for shaping a productive future" (p. 5). Providing students with an environment that develops their mathematical abilities and further nurtures creativity in the domain should be a premier goal for educational systems that seek to foster creative leaders of societies who can contribute to making life better. However, current dominating practices that is based on providing special enrichment programs only outside the classroom is not adequate; as creativity should be nurtured for all students, as well as that such special enrichment programs are hindered by identification procedures that might overlook some gifted students due to the ambiguous nature of creativity and giftedness (Wadaani,2015a).

Literature includes different theories and principles of creativity, which has resulted in different constructs, factors and levels (Rhodes, 1961; Davis, Rimm, \& Siegle, 2011). Some of these theories provided a narrow restricted perspective, and others discussed creativity in a broad view (Wadaani et al., 2016). Creativity has been defined as a life style, as a factor of effective learning, as a component of giftedness, as a separate category of talent, and as original productivity (Wadaani, 2015b). Plucker, Beghetto, and Dow (2004), for example, described creativity as "the interaction among aptitude, process, and environment by which an individual or group produces a perceptible product that is both novel and useful as defined within a social context" (p. 90). Creativity also is included in dominating broad theories of intelligence where creativity was viewed as an aspect, as well as an outcome of intelligence (e.g., Gardner, 1983; Sternberg, 1985).

One of the prominent approaches to understanding creativity is the humanistic approach, which has been influential as the essence of broad contemporary conceptions of creativity (Davis, 2004). According to Maslow (1943, 1968) and Rogers (1954) creativity is related to self-actualization as a high level personal need that requires prior fulfillment of other basic needs including physiological, safety, social, and esteem needs. Maslow (1943) pointed out that self-actualization refers to "the desire for self-fulfillment and being everything that one is capable of becoming" (p. 382). Rogers (1954) added that the need of self-actualization is the motive of creativity; self-actualization, on the hand, involves prerequisite personal and environmental conditions that support an internal locus of evaluation, feeling of worth, and freedom of expression. Maslow (1943) further described that creative behaviors and product are affected by satisfaction of basic needs. Accordingly, Maslow and Rogers' theories of creativity suggest that the creative person is "a self-actualizing human being who is mentally healthy, self-accepting, democratic minded, fully functioning, and forward growing using all of his/her talents to become what he/she is capable of becoming" (Davis, 2004, p. 2). 
Based upon previous foundations, creativity can be described as a multifaceted human development phenomenon that includes a broad range of personality characteristics, life skills, general mental skills, and domain-related skills (Wadaani, 2015b). Demonstrating evolving skills related to a certain academic domain can be a sign of creativity in that domain; mathematical creativity for example. Signs of creativity in mathematics can be further developed in order to reach the highest level of creativity, which represents the production of novel solutions that extend knowledge in the domain.

Creativity in mathematics also lacks a common definition; however, mathematicians agree that creativity is a major element of mathematical activities (Yuan \& Sriraman, 2011; Lee, Hwang, \& Seo, 2003). Contemporary mathematics educators view creativity as "an orientation or disposition toward mathematical activity that can be fostered broadly in the general school population" (Silver, 1997, p. 75). Mann (2006) pointed out that creativity is the essence of mathematics and the most influential factor of effective learning, mathematical talent development, and future mathematical accomplishments. Leiken (2009) also indicated that mathematical creativity is "the dynamic property of the human mind and each child's creative potential can be developed and realized, or on the contrary, deprived" (p.129).

Sriraman (2005) added that although creativity in mathematics is often looked at as the exclusive domain of professional mathematicians, "students at the general education level are capable of creativity" (p.86). He explained that at the professional level, mathematical creativity can be defined as the ability to produce original work that significantly extends the body of knowledge, and/or one who opens up avenues of new questions for other mathematicians. On the other hand, mathematical creativity in school settings can be defined as "the process that results in unusual and/ or insightful solutions to a given problem or analogy problems; and/or the formulation of new questions and/or possibilities that allow an old problem to be regarded from a new angle requiring imagination which is similar to those for creativity in professional mathematics" (p.24).

Creativity also is included as a component in the prominent theories of giftedness (Kaufman, Plucker, and Russell, 2011). Theory of Renzulli (2005), for example, includes giftedness as emerging from the interaction of three components: above average ability, creativity, and task commitment. The National Association of Gifted Children NAGC (2010) published a position paper proposing a definition of giftedness that emphasizes talent development as a lifelong process. Subotnik, Olszewski-Kubilius, and Worrell (2012) indicated "giftedness can be viewed as developmental in the beginning stages in which potential is the key variable" ( $p$. 176). Giftedness, however, has been used interchangeably with the concept of talent, and both are defined in different ways with no one definition that is universally accepted (Davis, Riman, \& Seigle, 2011).

In turn, mathematical giftedness and talent can be demonstrated in a variety of ways. Although academic achievement in mathematics is a strong predictor of mathematical talent, the absence of academic achievement does not necessarily mean the absence of potentials. Students are different in terms of being stimulated to express their academic abilities, and "absence of evidence is not evidence of absence". Sheffield (1994) stated that "the frequent narrow definition of gifted mathematics student is scoring above the 95th percentile on a test of mathematical achievement" (p. 3). NCTM defines the group of students with high ability in mathematics as mathematically promising; the NCTM Task Force on Mathematically Promising Students identifies mathematical promise as "a function of ability, motivation, belief, and experience or opportunity with large range of abilities and a continuum of needs that should be met" (Sheffield et al., 1999, p. 310).

As a result of this ambiguity and overlap between many concepts including academic achievement, giftedness, talent, intelligence, and creativity; it is difficult to achieve accuracy in the first critical process to provide gifted students with special enrichment programs; identification processes. The identification processes of gifted students for special educational services do not only lack clear definitions of giftedness and talent, but also are affected by many other factors such as psychological and cultural factors. Therefore, the likelihood that some gifted students are excluded from special pull-out educational services does exist (Davis, Rimm, \& Siegle, 2011; Wadaani, 2015a).

Therefore, general classrooms in many schools may include gifted students who are not identified as gifted and deprived from additional special enrichment services because of an inaccurate identification process, or because their schools do not offer special programs for gifted and talented students. Based upon that, and taking into account the need of nurturing students' creativity and the importance of supporting gifted students in general classrooms, teachers should internalize broad conceptions of creativity and talent, work to foster creativity skills for all students, and provide additional enrichment opportunities for those who have high abilities in general classrooms (Wadaani, 2015a).

Burleson (2006) indicated that notable psychologists agree that learning is enhanced when it is pursued as a creative and self-actualizing passion. Treffinger, Young, Selby, and Shepardson (2002) added that deliberate efforts to nurture creative thinking skills are important components of excellent educational programs. In mathematics education field, creativity is considered the essence that should not be neglected in general classrooms in order to facilitate the development of young mathematicians (Mann, 2006; Leikin \& Pitta-Pantazi, 
2013). Encouraging creativity in mathematics classes is important for all students to enjoy working in mathematics and to develop meaningful understanding of mathematical concepts. It is more important for students who have high abilities in order to develop their mathematical talent and to become more creative and future mathematicians.

However, nurturing creativity and supporting mathematical talent development in general education schools requires that teachers hold clear understanding of theses multifaceted interrelated concepts, hold positive attitudes toward gifted education, and have facilities and support to teach for creativity and mathematical talent development. Following is a proposed developmental model for further clarification of such concepts and phases regarding creativity and mathematical talent development; teaching for creativity and teaching for mathematical talent development are included as the two major parts of the model that can be utilized for a sequence of student development in mathematical proficiency; gifted, talented, and mathematicians. This model is based on a conceptual framework that includes creativity in mathematics as a malleable multi-level ability, which is considered the essence of mathematical learning and accomplishment. With assumption, all students have the potential of expressing and developing mathematical creativity, and some of the them may further advance in mathematics to a level of mathematical talent development which results in original impacts in the domain.

\section{Results and Discussion}

Teaching for Creativity and Mathematical Talent development (T-CMTD) is a recommended model for supporting creativity and mathematical talent development in general education schools based on clear understanding and positive beliefs about student capability of success. T-CMTD requires that teachers hold positive attitudes toward effective teaching as a process of human development. Teachers who hold positive beliefs and passion for effective teaching will look for professional development opportunities, so he/she can use different teaching methods and provide additional options that nurture creativity and mathematical talent based upon students' needs and the situation of each education setting.

In order to teach for creativity and mathematical talent development, teachers should understand their roles as a facilitator of optimal human development, conceptualize creativity as an ongoing process of self-development, and hold positive beliefs about student capability for success. The mission is to provide opportunities for all students to develop academic, personal and social skills necessary to become successful individuals, increase their achievement to reach the highest level possible, become gifted, then talented, and perhaps become future mathematicians.

Adopting T-CMTD as a model of teaching entails that creativity is perceived as "Human Development toward Self-Actualization". Self-actualization was defined by Maslow (1943) as "the desire for self-fulfillment and being everything that one is capable of becoming" (p. 382). The humanistic self-actualization approach to creativity (Maslow, 1943; Rogers, 1954; Maslow, 1968) has been supported either explicitly or implicitly by many scholars. According to Davis (2004), the relationship between creativity and self-actualization is one of the most influential concepts in the field of creativity, and argued that creativity is a way of thinking and living that leads to personal development and a productive successful life. Creativity, as human development, includes a broad range of personality characteristics, life skills, general mental skills, and domain-related skills (specialized creativity).

On the other hand, mathematically gifted students could be viewed as individuals who have above average aptitudes in mathematics with average general intelligence, and task-commitment with strong motivation and attitudes toward continued learning and applications of mathematics in real life situations (creativity: personality). The giftedness with above average general intelligence can turn to become talent if creativity (creativity: person and process) is developed as a major component of talent development. Original productivity in the discipline (creativity: person, process, and product) requires not only talent, but also more time, task commitment, and further environmental support for creativity (creativity: person, process, product, and press/environment). Teachers should help each student through T-CMTD to reach the highest level possible of overall development including maximizing academic achievement, nurturing creativity and mathematical talent along with personal and social skills necessary for authentic growth and life success

Teaching for Creativity in this case means facilitating ongoing overall development of humans/students that leads them to positively actualize themselves and reach the highest level possible appropriate for their special aptitudes, potentials, circumstances, and community needs. As the highest level of self-actualization may vary from an individual to another, students should be facilitated to develop positive belief systems related to their personal abilities, achievement goals, and future success; and lead them to keep an active and regenerated desire for self-actualization through unlimited high-level personal goals of achievement. Based on T-CMTD philosophy, teachers should teach for creativity for all students considering each student's unique aptitudes, and circumstances, as well as the educational situation. Teaching for creativity requires certain classroom conditions and teaching practices, as discussed in the literature review, that provide a healthy environment for all students to express and develop their creativity and mathematical abilities. The following model, Figure 1, illustrates the researcher's view of Teaching for Creativity and Mathematical Talent development (T-CMTD). 


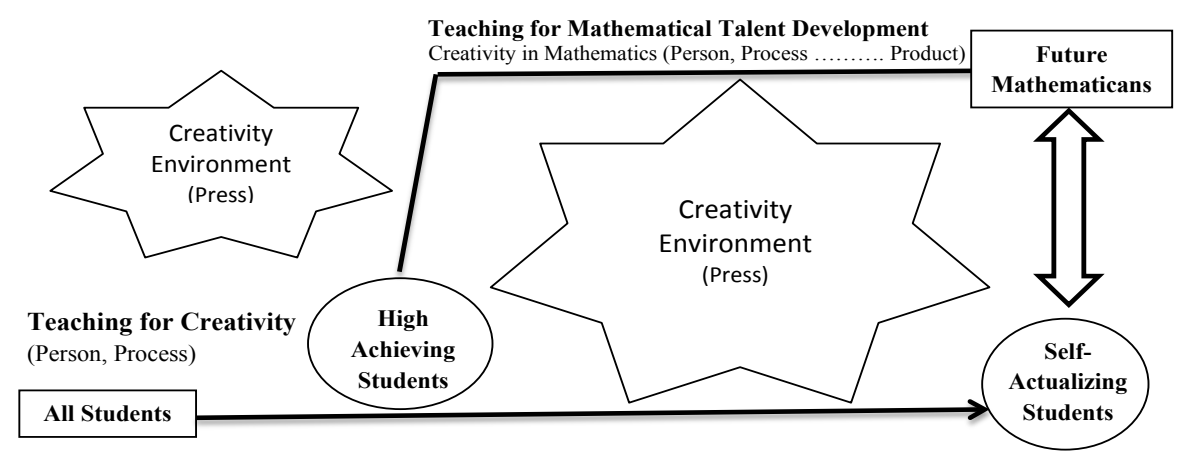

Figure 1. Model of Teaching for Creativity and Mathematical Talent Development T-CMTD

Creativity in Phase I of this model can be viewed as general learning, personal, and social skills; it might be mathematical creativity at a low level. All students benefit from the creativity atmosphere in Phase I, move forward in their meaningful effective learning and personal/social development, and may express giftedness in mathematics later. It is highly possible that some students are encouraged to express high ability in mathematics/ high achievement/ giftedness, and it is also possible that other students are influenced and enhanced by the creativity environment to systematically work hard to achieve self-actualization, and may extend their abilities and become potentially gifted. Students who have high potential in mathematics should be provided with additional enrichment opportunities, Phase II.

In Phase II, gifted students are facilitated to further develop their potential mathematical talent and creativity in mathematics, for being future mathematician who can develop original produces with time, if intrinsic motivation/task commitment and environmental support for creativity continue to be available. The focus in Phase II is on mathematical creativity development, but it does not mean neglecting the development of general creativity as skills of effective learning, personal, and social growth, which should be an ongoing development process for all students as the essence of the philosophy of teaching for creativity and mathematical development. In phase II, possible services for the gifted students include special activities and programs inside or outside the classroom that can be extended for further enrichment out-of-school environment. The aim of this model is not only to develop mathematical talent, but also to develop necessary skills for all students to be effective creative continued learners, which leads them to high level of self-actualization. Perhaps some of them move further ahead, with enrichment programs, to be mathematicians with needed personal and social skills that make their contributions in the field and their society more effective and valuable.

Effective teaching practices depend on several factors related to the components of each educational situation. Best decisions related to teaching methods used are expected from teachers themselves; teachers, as classroom experts, should understand more than others what might effectively help their students achieve desired goals in each educational setting. Teaching practices for developing creativity and mathematical talent might include, but are not limited to, ensuring that students have prior knowledge and needed skills to succeed in the new topic, using advanced organizers and inquiry activities to help students construct knowledge and skills, providing needed learning tools with utilization of technology, allowing independent thinking, encouraging multiple methods and responses, informing students of the creative process and creative individuals, developing creativity as personal/social/life skills, developing creativity as a process/thinking skills, assigning heterogeneous group tasks, helping students feel safe and enjoy learning, encouraging social communication/ sharing, respectfully discussing and evaluating of ideas, effectively using questions, providing positive feedback, building upon students' ideas, assigning group tasks, differentiating instruction and evaluation, helping students feel the aesthetics and benefits of mathematics using real life applications, and collaborating with significant others to provide additional remedy or enrichment activities such as tutoring and university level advanced experiences. T-CMTD might lead students to move through different developmental stages of academic and life success.

This model is based on the researcher's view, in light of theoretical literature, about the characteristics of the individuals in each level of mathematical proficiency development for the purpose of understanding T-CMTD. Although this model might be more applicable in the field of mathematics, especially that general IQ is included as a criterion; it does not propose a generalizable sequence of human development in mathematics or other fields as the researcher believes that human intelligence is an elusive phenomenon. Creativity in this model is an essential component that exists at each level of mathematical ability development. However, it has different elements at each level as creativity can be nurtured first as personality skills. Then it can be developed into personality skills and skills of thinking/processes, and later, after considerable time, continued environment support, hard work, and incubation, illumination may appear and novel ideas or products are released for verification; creativity in this case represents personality, process, press, and product. The following figure, Figure 2, simplifies the possible transitional stages of mathematical talent development through T-CMTD. 
Environment Support and Time

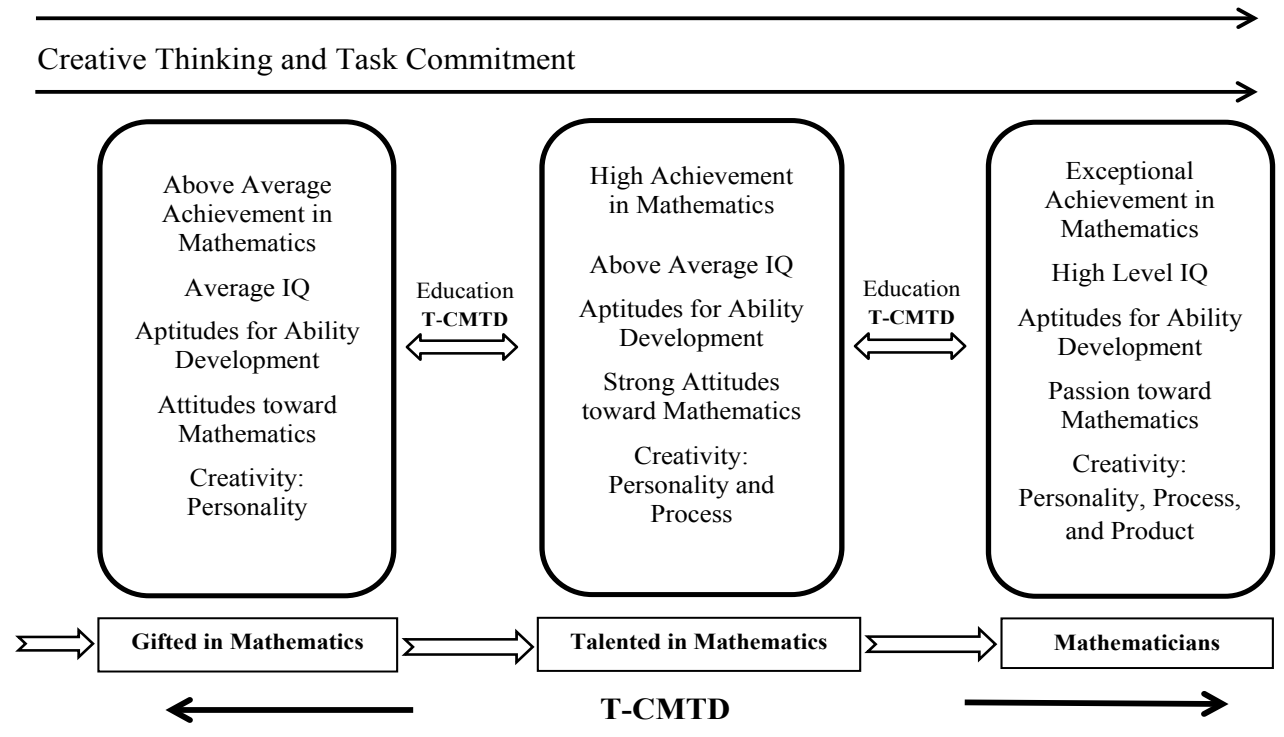

Figure 2. Potential Stages of Creativity and Mathematical Talent Development through T-CMTD

The T-CMTD model is designed to have an open gate for any student to become gifted in mathematics and to develop their potentials for being talented and future mathematician if certain conditions are met with continued availability and ongoing utilization. These conditions are related to environment, personality, and time. Although it is rare that students in K-12 schools highly accomplish in mathematics to the level of mathematicians, they still should be facilitated toward achieving this aim at a future time with positive beliefs about student capability for success. Accordingly, T-CMTD model is recommended to be utilized for establishing the optimal school environment for facilitating students to move toward the highest level possible of these developmental stages in mathematical accomplishment.

However, the focus group interview with a sample of mathematics teachers revealed multiple types of requirements for the effective utilization of this model in actual environments of general education schools. The qualitative data was transcribed and organized to be around several key aspects including teachers, classrooms setting, school leadership and curriculum objectives. The study sample of teachers showed support to the proposed T-CMTD and attitudes to get benefits from its elements, and they emphasized some major needs that are essential for them to be able to apply the model in the best possible way. They indicated the need for effective professional development in the field of creativity and gifted education at school-district training level, and at university program level including more preparation at this type of models.

Teachers also mentioned that the effective application of the T-CMTD model requires some changes in school policies and classrooms set-up, where they pointed out requirements of fewer classroom teaching hours per-week
(15 maximum), with fewer students in each classroom (20 maximum). From teachers' perspectives, these modifications would allow time space for them to plan and well prepare for using such effective teaching models. Other requirements for effective application of the T-CMTD proposed model discussed by the sample of this study also included improving school facilities such as science and mathematics lab, reconsidering the appointment process of school leadership team members and providing appropriate education for them to become more supportive to teachers in using new effective model of teaching. Teachers who were participated in this study also argued about leaning objectives that are emphasized in current curriculum as they indicated the need for shifting the focus in current curriculum toward life direct learning objectives that reflect on student authentic development.

Overall, the proposed T-CMTD model seemed to be clear and attractive for teacher to adopt, however, current school environments might be not fully ready to include this model, as teachers in this study indicated multiple basic requirements for its effective application. Therefore, educational policy makers and stakeholders are invited to consider such needed development in education system that allow using new proposed promising teaching models for human development.

\section{Conclusions}

Literature includes multiple perspectives about creativity and giftedness, but the dominating perspective is the one that is based on broad liberal conceptualization of creativity and giftedness with positive beliefs about student capability of success and development. 
Accordingly, school environments and teachers' attitudes are supposed to be built according to this comprehensive developmental view, with the belief of education as a process of human development. Based upon that, this research study synthesized supportive literature for a proposed model that aims at helping teachers get deep understanding of creativity and mathematical talent development in school settings; Teaching for Creativity and Mathematical Talent Development T-CMTD. Teaching practices are recommended to be aligned with clear understanding of creativity and talent development as illustrated in this proposed model. Major requirements of best utilization of this model were discussed to include relevant teacher education and training, less teaching load, effective facilities and appropriate classroom size, school leadership support, and curriculum modification. It is also recommended that researchers make additional critical review of the proposed T-CMTD model and conduct multiple pilot studies to get a scientifically better version that can be utilized in different circumstances of school environments.

\section{REFERENCES}

[1] Bahar, K., \& Maker, J. (2011). Exploring the relationship between mathematical creativity and mathematical acheivment. Asia-Pacific Journal of Gifted and Talented Education, 3(1), 33-48. Retrieved from http://www.apfgift ed.org.

[2] Beghetto, R., \& Kaufman, J. (2007). Toward a broader conception of creativity: A case for "mini-c" creativity. Psychology of Aesthetics, Creativity, and the Arts, 1(2), 7379. doi: org/10.1037/1931-3896.1.2.73.

[3] Brinkman, D. (2010). Teaching creatively and teaching for creativity. Arts Education Policy Review, 111, 48-50. doi:10.1080/10632910903455785.

[4] Burleson, W. (2005). Developing creativity, motivation, and self-actualization with learning systems. International Journal of Human-Computer Studies, 63, 436-451. doi:10.1016/j.ijhcs.2005.04.007.

[5] Davis, G. (2004). Creativity is for ever. Dubuqe, IA: Kandall Hunt Publishing Company.

[6] Davis, G., Rimm, S., \& Siegle, D. (2011). Education of the gifted and talented. Boston, MA: Pearson Education.

[7] Gardner, H. (1983). Frames of mind: The theory of multiple intelligences. New York: Basic Books.

[8] Kaufman, J., Plucker, J., \& Russell, C. (2012). Identifying and assessing creativity as a component of giftedness. Journal of Psychoeducational Assessment, 30(60), 60-73. doi: $10.1177 / 0734282911428196$.

[9] Lee, K., Hwang, D., \& Seo, J. (2003). A development of the test for mathematical creative problem solving ability. Journal of the Korea Society of Mathematical Education, 7(3), 163-189. Retrieved from http://icms.kaist.ac.kr.
[10] Leikin, R. (2009). Bridging research and theory in mathematics education with research and theory in creativity and giftedness. In R. Leikin, A. Berman, \& B. Koichu, Creativity in mathematics and the education of gifted students (pp. 385-411). Rotterdam, The Netherlands: Sense Publishers.

[11] Leikin, R., \& Pitta-Pantazi, D. (2013). Creativity and mathematics education: The state of the art. The International Journal of Mathematics Education ZDM, 45,159-166. doi: 10.1007/s11858-012-0459-1.

[12] Mann, E. (2005). Mathematical creativity and school mathematics: Indicators of matheatical creativity in middle scholol students. Doctoral Dessertation, The University of Connectecut. Retrived from http://www.gifted.uconn.edu.

[13] Mann, E. (2006). Creativity: The essence of mathematics. Journal for the Education of the Gifted, 30(2), 236-260. doi: 10.4219/jeg-2006-264.

[14] Maslow, A. (1943). A theory of human motivation. Psychological Review, 50(4), 370-396. doi: 10.1037/h005 4346.

[15] Maslow, A. (1968). Toward a psychology of being. New York, NY: Harper.

[16] Miligram, R., \& Hong, E. (2009). Talent loss in mathematics: Causes and solutions. In R. Leikin, A. Berman, \& B. Koichu, Creativity in mathematics and the education of gifted students (pp. 149-161). Rotterdam, The Netherlands: Sense Publishers.

[17] National Association of Gifted Children (NAGC). (2010). Redefining giftedness for a new century: Shifting the paradigm. Washington, DC: NAGC. Retrieved from http://www.nagc.org.

[18] National Council of Teachers of Mathematics (NCTM). (1980). An agenda for action: Recommendations for school mathematics for the 1980s. Reston, VA: NCTM.

[19] National Council of Teachers of Mathematics NCTM . (2000). Principles and standards for school mathematics. Reston,VA: NCTM.

[20] Plucker, J., Beghetto, R., \& Dow, G. (2004). Why isn't creativity more important to educational psychologists? Potential, pitfalls, and future directions in creativity research. Educational Psychologist, 39, 83-96. Retrieved from http://eric.ed.gov.

[21] Renzulli, J. (2005). The three-ring definition of giftedness: A developmental model for promoting creative productivity. Storrs, CT: The Naeg Center of Gifted Education and Talent Development, University of Connecticut. Retrieved from http://www.gifted.uconn.edu.

[22] Rhodes, M. (1961). An analysis of creativity. Phi Delta Kappan, 42, 305-310. Retrieved from http://www.jstor.org.

[23] Rogers, C. (1954). Toward a theory of creativity. ETC: A Review of General Semantics, 11, 249-260. doi: 1955-05283-001.

[24] Sheffield, L. (1994). The development of gifted and talented mathematics students and the national council of teachers of mathematics standards. Storrs, CT: The National Research Center on the Gifted and Talented,The University of Connecticut. 
[25] Sheffield, L. (1999). Serving the needs of the mathematically promising. In L. Sheffield, Developing mathematically promising students (pp. 43-55). Reston, VA: NCTM.

[26] Sheffield, L. (2013). Creativity and school mathematics: some modest observations. The International Journal of Mathematics Education ZDM, 45, 325-332. doi: 10.1007/s11858-013-0484-8.

[27] Silver, E. (1997). Fostering creativity through instruction rich in mathematical problem solving and problem posing. The international Journal of Mathematics Education ZDM, 3, 75-80. doi: 10.1007/s11858-997-0003-x.

[28] Sriraman, B. (2005). Are giftedness and creativity synonyms in mathematics? The Journal of Secondary Gifted Education, 17(1), 20-36. doi: EJ746043.

[29] Sriraman, B., Yaftian, N., \& Lee, K. (2011). Mathematical creativity and mathematics education: A derivative of existing research. In B. Sriraman, \& K. Lee, The elements of creativity and giftedness in mathematics (pp. 119-130). Rotterdam, The Netherlands: Sense Publishers.

[30] Stanley, J. (1991). An academic model for educating the mathematically talented. Gifted Child Quarterly, 35(1), 36-42. doi: 10.1177/001698629103500105.

[31] Sternberg, R. (1985). Beyond IQ: A triarchic theory of human intelligenc. New York: Cambridge University Press.

[32] Sternberg, R. (2010). Teaching for creativity. In R. Beghetto, \& J. Kaufman, Nurturing creativity in the classroom (pp. 394-414). New York, NY: Cambridge University Press.

[33] Sternberg, R., Kaufman, J., \& Grigorenko, E. (2008). Applied intelligence. New York, NY: Cambridge University Press.

[34] Subotnik, R., Olszewski-Kubilius, P., \& Worrell, F. (2012). A Proposed direction forward for gifted education based on psychological science. Gifted Child Quarterly, 56(4), 176-188. doi: 10.1177/0016986212456079.

[35] Torrance, E. P. (1995). Insights about creativity: Questioned, rejected, ridiculed, ignored. Educational Psychology Review, 7(3), 313-322. doi: 10.1007/BF02213 376.

[36] Treffinger, D., Young, G., Selby, E., \& Shepardson, C. (2002). Assessing creativity: A guide for educatores. Storrs, CT: The National Research Center on the Gifted and Talented. Retrieved from http://eric.ed.gov.

[37] Wadaani, M. R. (2015a). Teachers attitudes and features of support related to teaching for creativity and mathematical talent development in the United States. Lwarence, kansas, USA: University of Kansas, Doctoral Dissertation.

[38] Wadaani, M. R. (2015b). Teaching for creativity as human development toward self-actualization. Creative Education, 6, 669-679. doi: 10.4236/ce.2015.67067.

[39] Wadaani, M. R., Seidl, M., Mends, D., Lagat, A., Edgar, K., Degnan, K., Kunnen, E. (2016). Education and human development. New York, NY: Magnum Publishing LLC.

[40] Yuan, X., \& Sriraman, B. (2011). An exploratory study of relationships between students' creativity and mathematical problem-posing abilities: Comparing Chinese and U.S students. In B. Sriraman, \& K. Lee, The elements of creativity and giftedness in mathematics (pp. 5-28). Rotterdam, The Netherlands: Sense Publishers . 